\title{
Investigating the effects of improving public transport system linkage to spatial strategy on controlling urban sprawl: evidence from Surabaya City, Indonesia
}

\author{
L. Ambarwati ${ }^{1,2}$, R. Verhaeghe ${ }^{2}$, A. J. Pel ${ }^{2}$ \& B. van Arem ${ }^{2}$ \\ ${ }^{1}$ Department of Transport and Planning, TU Delft, Netherlands \\ ${ }^{2}$ Department of Civil Engineering, Brawijaya University, Indonesia
}

\begin{abstract}
The phenomenon of sprawl has been a huge issue since the beginning of the $20^{\text {th }}$ century and is characterized by rapid and unbalanced settlement development, with transportation network, particularly in the suburban areas. Academic research has explained the linkage strategy between transportation network and urban planning. However, insufficient empirical verification has been carried out to reduce this phenomenon by using the integrated approach of space-transport development. This paper focuses on analyzing the improvement of public transport supply incorporated in the settlement development. The improvement of public transport (PT) is designed by planning Mass Rapid Transit (MRT), Light Rapid Transit (LRT), Bus Rapid Transit (BRT) and feeder systems. The impact of PT improvement has an effect on the settlement development. In addition, creating a balance between employment and population density is designed as an alternative to urban spatial strategy. These approaches are necessary in order to analyze and to evaluate the many alternatives proposed as a solution to overcome this phenomenon. The conclusions reveal that the requirement for linkage space-transport development strategy in order to control settlement in the suburbs has to involve reduction of $35 \%$ in travel time and to increase doubling of the use of PT.
\end{abstract}

Keywords: public transport, spatial strategy-transport development, controlling urban sprawl, settlement development. 


\section{Introduction}

Regarding urban development, a city expands to the outskirts of an urban area. This phenomenon has occurred in all over the world. Most cities in Indonesia, it has created broad serious problems since the beginning of $20^{\text {th }}$ century. Urban sprawl has several features which impact on a low density zone, dependence on the automobile, spatial mismatch and job sprawling [1]. Several efforts to minimize the impact of this phenomenon have been made based on the previous researches. Discussion has been held on how to overcome this phenomenon by integrating activities into high density areas and land-use mixes in order to reduce vehicular travel [2]. Firstly, by considering the transportation role in combating the problems related to urban sprawl [3], secondly, by considering the provision of a public transport system at the suburban destinations for Greater Dublin Area (GDA) [4].

According to [5], the urban containment strategies are some of the bestknown planning instruments for managing urban sprawl. These include greenbelt and urban growth boundaries as applied in Switzerland since 1970. The strategies particularly the boundary, have restricted development to building zones and have promoted increased building density. The study specifically concentrated on an urban strategy to minimize the urban sprawl.

Other researcher has paid attention to the relationship between employment suburbanization and the growth of reversed commuting in the weekday travel behavior of working residents in Paris [6]. The findings of the research have confirmed that the choice of transport depends on the workplace, and the gentrification of the municipality of Paris linked to its capacity to attract highqualified jobs and to its proximity to sub-centers. If quality of public transport remains insufficient, high-income residents resort to use their car greater extend. The research recommended that public authorities should be aware of this spatial mismatch which has negative environmental and social consequences. Other research related to urban development strategy such as a compact city approach employed in Istanbul to control urban sprawl by developing different scenarios. The result demonstrated that urban sprawl can be reduced by up to $62 \%$ through implementing certain spatial strategies [7].

Empirical research has been conducted insufficiently on the control of urban sprawl related to public transport network, taking into consideration of urban strategy and environmental impact of these developments and the commuter travel behavior. This paper will present a strategic option concentrated on the effort to integrate the spatial and transport plan to control settlement in the suburbs, particularly in poorly planned cities of developing countries. Sprawling settlement has grown in cities of developing countries since the 1980s.

This research will investigate the phenomena of transport mode choice, offering comparison for improvement of public transport and spatial strategy such as better balance between employment and population density and their consequences of alternatives in travel behavior of residents in suburban areas. 
The research will be analyzed by applying JSM (Java Spatial Model) and OmniTRANS model, by using micro video data to estimate PCU (passenger car unit) value for motorcycle, travel survey by distributing questionnaires to the residents to estimate the distribution parameters of travel behavior and value of time (VOT), employment and population data from National Census 2010. The findings of this research are expected to assist government authority in planning housing development in relation to transport network surrounding them, by proposing a structured process of employing potential alternatives.

The organization of paper is described as follows: data collection and explanation of methodology is explained in the second section. The third section comprises an estimation of parameters for four-step transport model from observation data. The fourth section discusses the assessment and comparison of settlement development in suburbs under three scenarios: current trend in 2030, improvement of public transport, and balance of employment and population density. The final section presents conclusions and recommendations for further analysis.

\section{Data and methods}

\subsection{Data and methods}

In this paper, four scenarios have been applied for Surabaya City to identify the alternative improvement with linkage of urban-transport development. This alternative is proposed as the basis for the urban planner decision in delivering a more sustainable development for Surabaya City. The alternatives include improvement of improvement of Mass Rapid Transit (MRT) and Light Rapid Transit (LRT), integrated PT-system consisting of MRT, LRT, BRT and feeder systems, an urban settlement development such as better employment and population balance in density, linkage of integrated PT-system and urban settlement strategy. The alternatives are analyzed by applying JSM (Java Spatial Model) and OmniTRANS model.

To apply the models, the data was collected for each village (called "Desa") within urbanized area of Surabaya City. Surabaya City the capital city of East Java Province, comprises 31 districts and 163 villages with a total area of 327 $\mathrm{km}^{2}$. The city has a population of approximately 3.024 million, with a high density of more than 11,000 persons per $\mathrm{km}^{2}$, which can be indicated as a highly urbanized area as seen in Figure 1 [8]. Population data was collected from National Census 2010. Other data was obtained by using micro video data and by distributing questionnaires to 163 villages (approximately 554 respondents). The questions consist of three parts which are socio economic background, trip characteristic, transport mode choice. The video data was employed to estimate PCU (passenger car unit) value for motorcycle, while questionnaires were used to estimate the distribution parameters of travel behavior and value of time (VOT). 


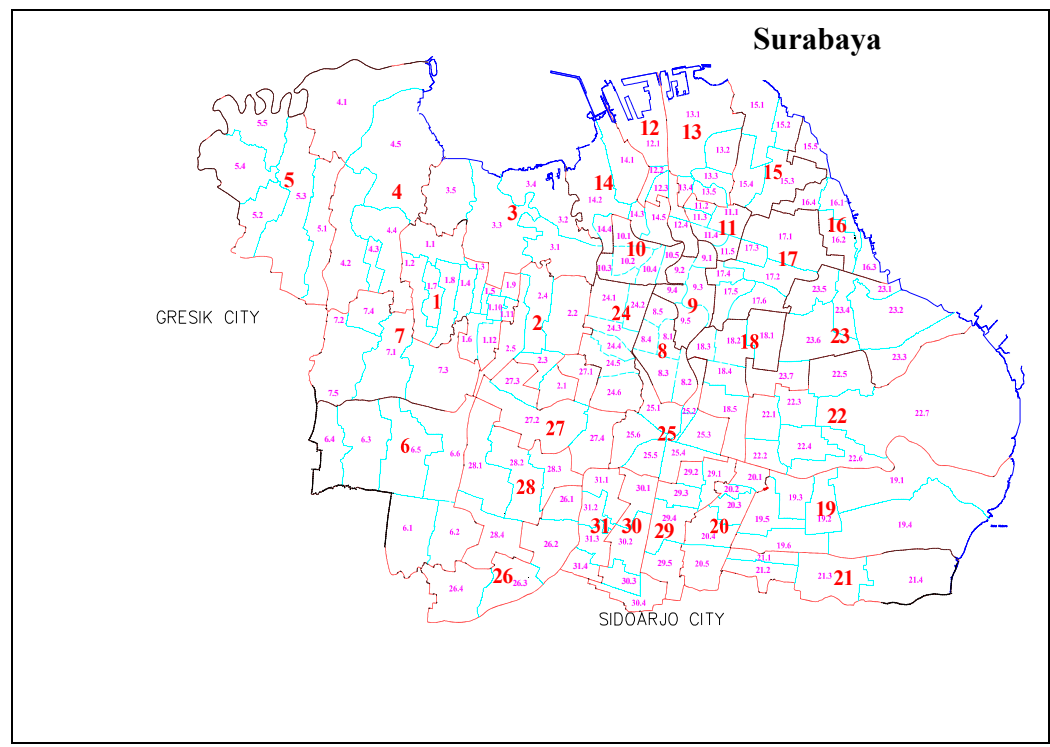

Figure 1: Location of study area (Surabaya City), Indonesia.

\subsection{Models}

The models employed in this research are Java Spatial Model (JSM) and OmniTRANS. The main point of this research is to achieve optimization of the transport network by proposing alternatives for the performance of improvement of public transport combined with a change of settlement strategy.

In JSM (Java Spatial Model), a spatial settlement model is analyzed with the input of the statistic for population and employment in 2010 census, socio-economic data and prevailing situation of land-use. The output of JSM (projection of population, employment, and housing area) would be used to generate the traffic demand in 2010 and 2030 by OmniTRANS. There are some alternatives proposed for the existing and the future conditions. Assessment of socio-economic data and spatial allocation data of Surabaya City in 2030 is based on forecasting economic growth in 2010. A detailed description of JSM can be seen in Figure 2.

OmniTRANS model is employed to set up a transport model. The transport model uses the four-step model for modelling trips between zones. In OmniTRANS model, the choices involved in making trip are included in the first step, with zonal data, such as number of residents or employments, as input. In this step, trip frequency parameters are used to determine trip productions and attractions to work, journey to school, or other activities per zone.

The result of trip frequency choice is input for the next step. In OmniTRANS models, the second and third steps are applied simultaneously by employing travel resistances and distribution functions per mode. The travel resistances are calculated by OmniTRANS, in a process called 'Skim Generation', by using the 
networks of each mode as an input. The outputs of the combined second and third step are OD-matrices for every mode. These OD-matrices are used in the last step together with the travel resistances, where all the OD-pairs are assigned on the network to each transport mode by modeling route choice. This can influence the travel resistances since these will increase congestion. Therefore, the traffic assignment becomes an iterative process. It is also possible to expand this feedback loop in OmniTRANS to include the second and third steps. The resulting outputs of OmniTRANS are link loads, travel times, travel distances and travel costs. The four-step model of transport model is explained in Figure 3.

Comparative analysis is undertaken to assess and to evaluate the technical performance of the different alternatives. The analysis consists of two alternatives of improvement of PT-systems which is assessed to obtain the best transport for Surabaya City, and alternative with better balance between employment and population density in developing spatial strategy. There are 5 alternatives proposed in this assessment consisting of scenarios for 2010 - the existing condition, scenario for 2030 with current trend, scenario for 2030 with improvement of public transport (combination of MRT and LRT systems, and design of MTR, LRT.BRT systems), and space-transport development by combination of improvement of PT-system and spatial strategy.

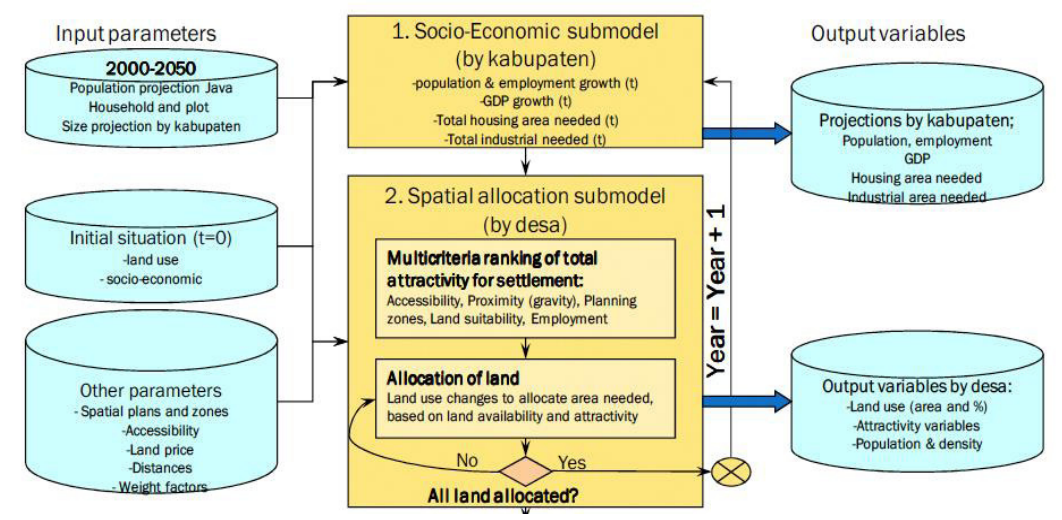

Figure 2: JSM framework 2.2 for 6 Ci's project [9].

\section{Estimation parameters for four-step transport model}

User behavior function is a requirement as input in OmniTRANS. The parameters of these functions are necessary to be estimated, the result of empirical analysis of porous flow model [11] to estimate PCU value of motorcycle, distribution parameter (using the top lognormal distribution) and value of time parameter from data by distributing questionnaires, parameters for BPR function and the crowding function in public transport from literature. 


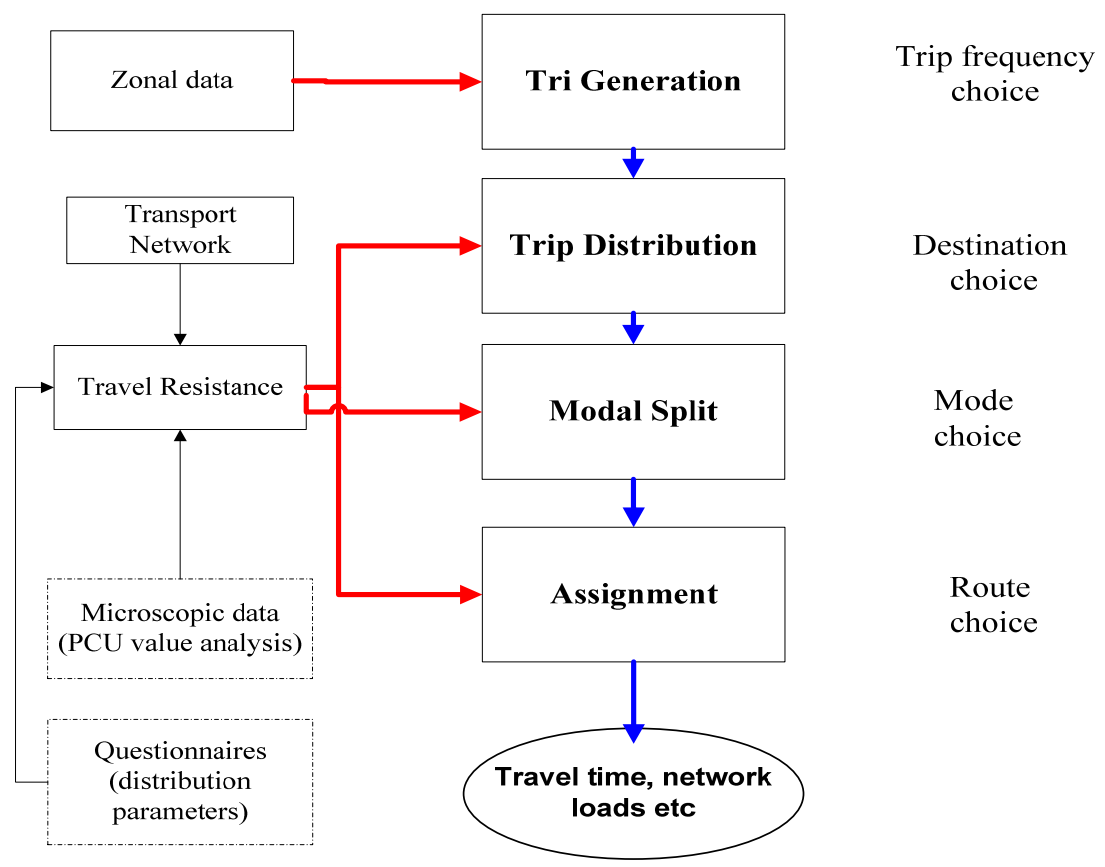

Figure 3: Four-step model ([10] and modified by author).

\subsection{Distribution parameters}

In the distribution step of OmniTRANS, trip distribution gives the relative willingness to make a trip as a function of the generalized travel costs cij. To determine the trip distribution, the model uses a top lognormal distribution function. This model used a doubly constrained gravity model which ignored the restriction that the distribution function has to be decrease consistently. Using an iterative approach (Furness), it balances the trips between each zone according to the travel cost while considering as much as possible the original constraints as imposed by the Productions and Attractions. The doubly constrained gravity model is explained as follows:

$$
T_{i j}=a_{i} b_{j} P_{i} A_{i} f\left(c_{i j}\right)
$$

where $T_{i j}$ is the number of trips from zone $i$ to zone $j, a_{i}$ is balancing factor for trips from zone $i, b_{j}$ is balancing factor for trips to zone $j, P_{i}$ is number of trips departing at zone $i, A_{j}$ is the number of trips arriving at zone $j, f\left(c_{i j}\right)$ : accessibility of zone $j$ from zone $i$ (distribution or deterrence function), $c_{i j}$ is travel resistance or impedance (in this case generalized cost). 
The top-lognormal function to assess the accessibility from zone $i$ to zone $j$ is presented as follows:

$$
F\left(c_{i j}\right)=\alpha c_{i j}^{\gamma} \exp \left(\beta \ln ^{2}\left(c_{i j}+1\right)\right)
$$

where $c_{i j}$ is travel impedance (generalized travel cost based on distance and time), $\alpha, \beta$, and $\gamma$ are coefficients.

The different (standard) values have been used for all transport modes (car, motorcycle, bicycle, public transport). Estimation of top-log normal parameters was based on the result of questionnaires distributed on September 2012. This model is used to obtain $\alpha, \beta, \gamma$ as coefficients in travel impedance for each transport mode that is incorporated in job description of Omnitrans. The result of calibration of distribution function parameters for every transport mode is shown in Table 1. Motorcycle is generally more attractive than the other transport modes. The result of distribution function is a function of travel time.

Table 1: Distribution parameters for each mode.

\begin{tabular}{|l|c|c|c|}
\hline Transport mode & $\alpha$ & $\beta$ & $\gamma$ \\
\hline Car & 31.696 & -0.0554 & 1.7603 \\
\hline Motorcycle & 38.99 & -0.0388 & 1.6564 \\
\hline Public transport & 8.848 & -0.0937 & 1.631 \\
\hline Bicycle & 5.45 & -0.025 & 0.85 \\
\hline
\end{tabular}

\subsection{PCU value for motorcycle}

The quantification of the vehicular interactions, in terms of Passenger Car Unit (PCU) under heterogeneous traffic is estimated by using the result of empirical analysis employing the porous flow model [11]. The values of different vehicle while moving in the heterogeneous traffic flow are provided a set of basic PCU value of these different types. In this research, the PCU value for motorcycle is estimated based on the specific motorcycle behavior as a major component in heterogeneous traffic flow.

Speed is the performance measurement from the empirical analysis which is employed to estimate the PCU values. Based on the relationship diagram between speed and density as shown in Figure 4, the analysis of PCU value is determined. By using a similar average speed for car and motorcycle, the PCU value for each speed group is determined. The average speed of car and motorcycle is classified in three groups, $40-80 \mathrm{~km} / \mathrm{hr}, 20-40 \mathrm{~km} / \mathrm{hr}$, and 0-20 $\mathrm{km} / \mathrm{hr}$.

Based on (3) which is introduced by [12], the PCU value is determined in each speed group by employing regression-fit analysis. The parameters which are approximated to linier model are assessed as PCU value for each speed group. Summary of examination of the regression-fit analysis is given in Table 2.

$$
\text { PCU.value.of.motorcycle }=\frac{\text { number.of } . \text { cars.removed }}{\text { number.of } . \text { motorcycle.added }}
$$




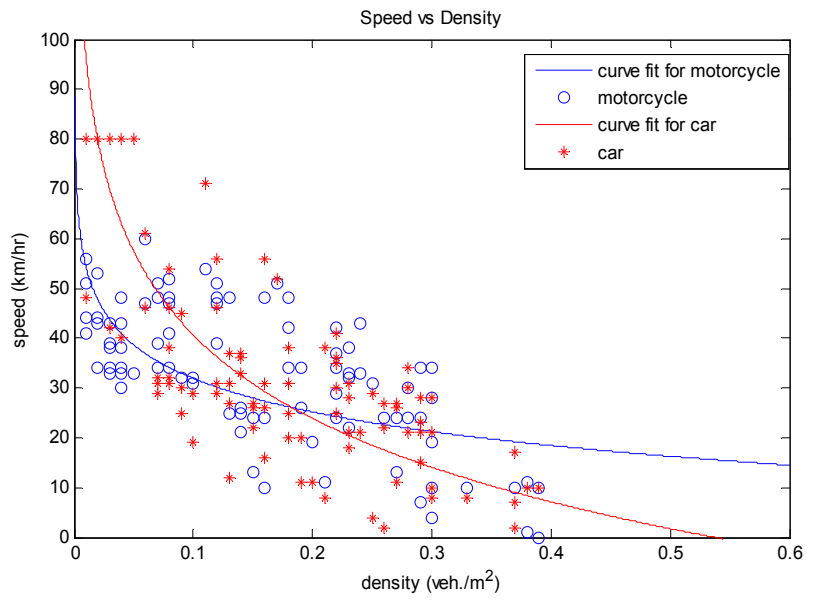

Figure 4: Speed-density diagram from the result of empirical analysis of porous flow approach.

Table 2: PCU value of each speed group.

\begin{tabular}{|l|l|}
\hline Speed group & PCU value \\
\hline $40-80 \mathrm{~km} / \mathrm{hr}$ & 0.294 \\
\hline $20-40 \mathrm{~km} / \mathrm{hr}$ & 0.309 \\
\hline $0-20 \mathrm{~km} / \mathrm{hr}$ & 0.502 \\
\hline
\end{tabular}

The variation of PCU for motorcycle is approximated to a linier model. From spot speed survey $42 \mathrm{~km} / \mathrm{hr}$, the PCU value for motorcycle is 0.304 . While, the PCU for bicycle is 0.24 established by research about conversion factor for bicycle using data in Shenyang, Tianjin and Shijiazhuang, China [13].

\subsection{Value of time}

The value of time (VOT) is input in OmniTRANS and is used in translating fare into time related to socio-economic background of residents in study area.

The VOT is estimated from distributed questionnaires through a revealed preference survey by a mode choice approach as explained as follows:

$$
\begin{gathered}
P_{q}=a_{i}+a_{2}\left(C_{p}-C_{q}\right)+a_{2}\left(T_{p}-T_{q}\right) \\
\operatorname{VOT}=\lambda=\frac{a_{2}}{a_{1}}
\end{gathered}
$$


where $P_{q}$ is transport mode choice of $q(\%), C_{p}$ is travel cost for mode $p$ (IDR), $C_{q}$ is travel cost for mode $q$ (IDR ), $T_{p}$ is travel time for mode $p$ (minute), $T_{q}$ is travel time for mode $q$ (minute), $\lambda$ is value of time, $a_{1}, a_{2}$ are parameters.

Based on (4) and (5), the VOT for motorized vehicle user is $32,837 \mathrm{IDR} / \mathrm{hr}$ while VOT for public transport passenger is $23,448 \mathrm{IDR} / \mathrm{hr}$.

\section{Alternatives relate to space-transport development}

\subsection{Current trend}

This scenario presents an analysis of the present (2010) and 2030 situation considering transportation aspects. The current 2010 scenario explains insight in the network and spatial performance of the Surabaya City in the present situation. 5\% of GDP, and employment growth $1 \%$ will be applied in this scenario. This scenario also notes the total of production and attraction into assessment

of interzonal production and attraction. The place with a high percentage of interzonal trips, contributes the high load in the network.

The current 2010 scenario by using 0.304 for PCU value of motorcycle, the result of modal split is equivalence with the traffic counting survey conducted in September 2012 as explained in Table 3.

The current trend 2030 scenario applied 5\% of GDP and 2\% of employment growth, while the change of socio economic and transport policy (such as local government planning for expansion of transport network with the extension of eastern ring road, and development of new collector and local roads) will be considered in the analysis. The projection is applied the demand of land-use needed for housing development, job places etc. without any improvements of public transportation and urban strategy approach.

Table 3: Modal split for 2010 scenario.

\begin{tabular}{|l|r|rr|}
\hline Transport mode & \multicolumn{1}{|c|}{$\begin{array}{c}\text { Modal split } \\
2010(\%)\end{array}$} & $\begin{array}{l}\text { Modal split from traffic } \\
\text { counting survey }\end{array}$ \\
\hline Public transport & 6.82 & & 5 \\
\hline Motorcycle & 57.98 & & 58.5 \\
\hline Car & 34.41 & & 35.9 \\
\hline Bicycle & 0.78 & & 0.6 \\
\hline
\end{tabular}

The result of production and attraction per mode choice for current trend in 2010 and 2030 steps is shown in Figure 5. The production bar chart explains the number of trips produced in each village/desa with the traveler originating in this desa. Citizens attract to the central urban area, even though many people live around the centre of Surabaya particularly in the northeast. The number of trips produced per village/desa in 2030 has increased. This situation indicates an 
increase of population and significant difference of growth rate for each desa. The trip attraction is related to amount of employment. The desa that has a high amount of employment results in a high trip attraction. Briefly, Figure 5 explains that there are several Desas located in suburban areas particularly in the west side, with similar production and attraction value to Desas in the central urban area.

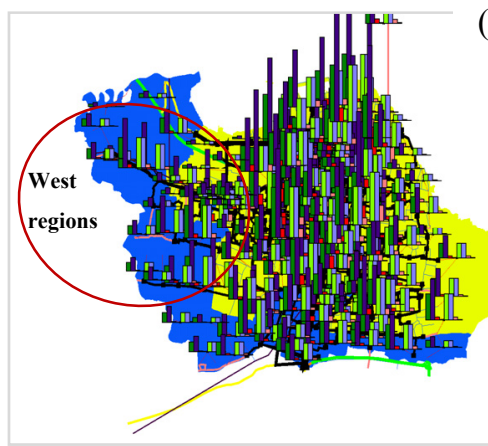

(a)

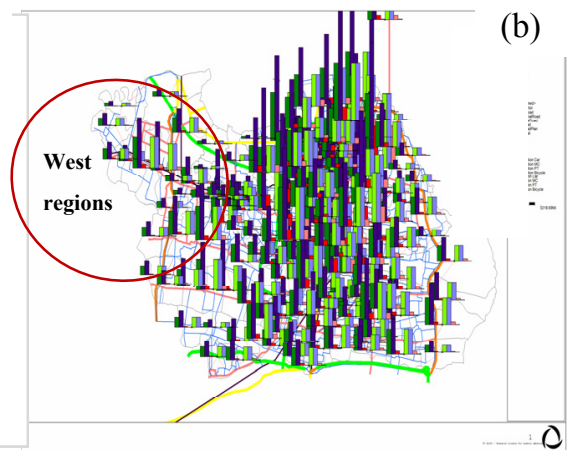

Figure 5: Production and Attraction per transport mode in 2010 (a) and 2030 (b).

Modal split indicates the percentage of trips for each transport mode. Table 4 describes increase of motorcycle and bicycle users from the current case of 2010 to the base case 2030, while the other transport modes are relatively fixed. It indicates that the motorcyclists and cyclists will increase $10 \%$ and $40 \%$ respectively without any change of public transport network. To minimize congestion, improvement of accessibility in these zones will be necessary for a sufficient public transport system. In addition, settlement development should be connected with the improvement of PT-system.

Table 4: Modal split for 2010 and 2030 scenarios.

\begin{tabular}{|l|l|l|}
\hline Transport mode & Modal split 2010 (\%) & Modal split 2030 (\%) \\
\hline Public transport & 5.82 & 5.62 \\
\hline Motorcycle & 58.73 & 63.39 \\
\hline Car & 34.88 & 30.23 \\
\hline Bicycle & 0.57 & 0.75 \\
\hline
\end{tabular}

\subsection{Improvement of public transport systems}

The alternatives to improve public transport network are planned to increase the accessibility for Surabaya City residents. Based on the previous research and design of the public transport network [14], this research considers the improvement of public transport by offering the alternatives with combination of MRT (monorail) and LRT (tram line), combination of MRT (monorail), LRT (tram line), regional train, feeder and trunk network as seen in Figure 6. 


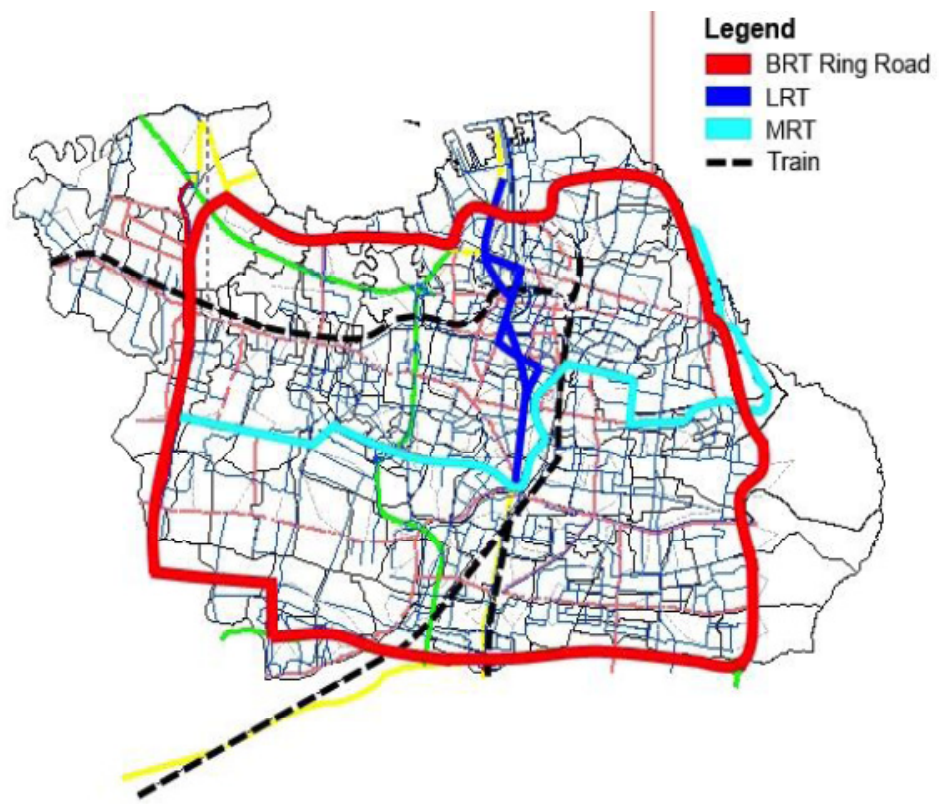

Figure 6: Public transport networks in the future for Surabaya City [14].

An evaluation of the performance of public transport improvement is conducted by considering the loads of public transport system for the alternatives given compared to the current base 2030. Figure 7 illustrates the loads of public transport system in the base case 2030 and in the alternatives. The load of all public transport systems for the alternatives is significantly different from the current base 2030, due to the great willingness of residents to change transport mode to the new public transport system alternatives. The first alternative is the design of new PT-system (MRT and LRT). The huge load of PT, particularly use of MRT system and feeder system, occurs in the west and central regions of the city. The second alternative (improvement of MRT, LRT, BRT and train systems) also revealed the similar trend of MRT and LRT passengers. This alternative is expected to accommodate residents' trips and to increase the accessibility of residents in the west region which is developed as settlement areas.

\subsection{The impact of urban strategy on residents accessibility}

For Surabaya City, this research examines implementation of balance between job and population density (compact city) linkage with improvement PT system. Interpretation results of the alternatives are explained as indicator of accessibility of residents particularly in the west region of city. The indicators are presented in modal split, distance and travel time per trip. 
(a)

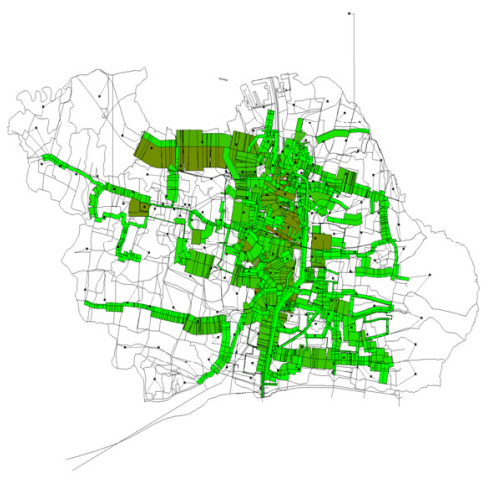

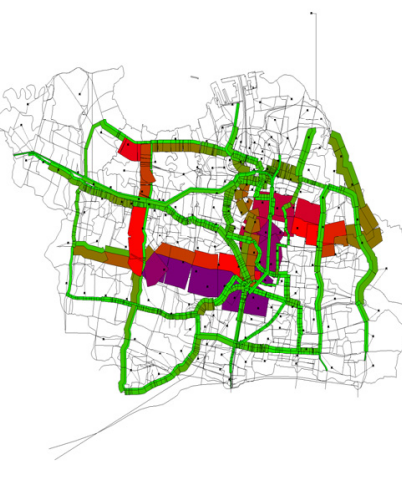

(b)

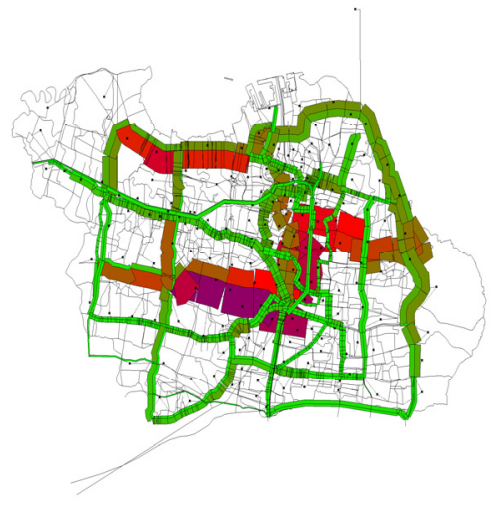

(c)

Figure 7: Load public transport networks in the current trend 2030 (a) MRT+LRT (b) and combination of all PT-systems (c).

(a)

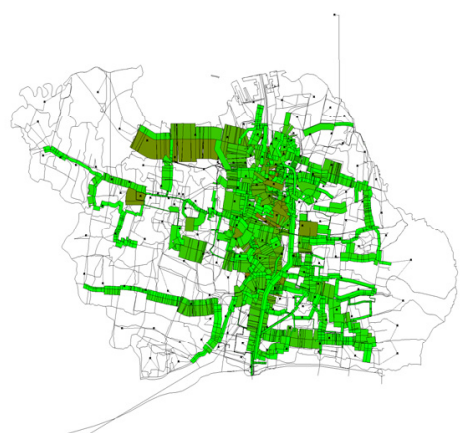

(b)

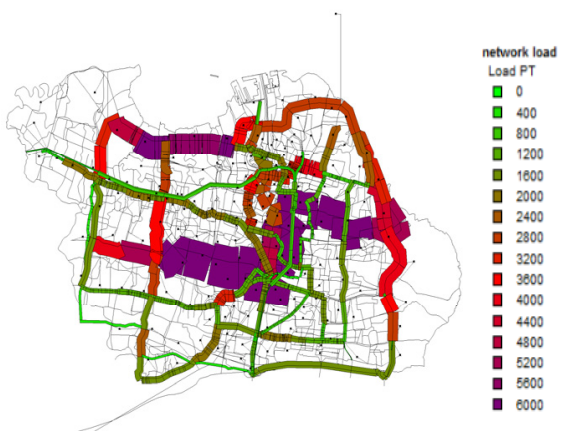

Figure 8: The load of PT network at current trend 2030 (a) and the scenario (compact city) (b). 
The loads in use of public transport network at current trend 2030 and the scenario (compact city) can be seen in Figure 8. The significant differences from the scenario current trend can be found in the loads of the PT network, particularly several zones in the west side and the northeast of the city. On the other hand, the compact city scenario has quite higher loads than the loads of scenario with only improvement of PT system.

Table 5: Modal split for 2030 base case and the alternative in 2030.

\begin{tabular}{|l|l|l|l|l|}
\hline $\begin{array}{l}\text { Transport } \\
\text { mode }\end{array}$ & $\begin{array}{l}\text { Modal split } \\
2030(\%)\end{array}$ & $\begin{array}{l}\text { Improvement of } \\
\text { MRT \& LRT } \\
(\%)\end{array}$ & $\begin{array}{l}\text { Improvement } \\
\text { of PT (\%) }\end{array}$ & $\begin{array}{l}\text { Space- } \\
\text { transport } \\
\text { development }\end{array}$ \\
\hline PT & 5.62 & 7.72 & 8.51 & 9.23 \\
\hline MC & 63.39 & 58.7 & 59.6 & 60.3 \\
\hline Car & 30.23 & 28.7 & 26.58 & 25.39 \\
\hline Bicycle & 0.75 & 5 & 5.04 & 5.09 \\
\hline
\end{tabular}

Table 5 indicates the modal split of 2030 current trend with the alternatives such as improvement of PT system (MRT and LRT), improvement of all PT systems, and design of space-transport development. The increase in public transport passengers for improvement of PT-system (MRT, LRT, and BRT, train) is $52 \%$, while the number of cyclist increases six times of the base case 2030. This finding means that the alternatives will increase significantly the use of public transport, which should be linked with bicycle facilities. On the other hand, the use of motorcycle has an insignificant effect on the alternatives. Briefly, an alternative is needed to reduce the use of motorcycle for example by simulation of decreasing the PT fare.

Table 6 and Table 7 explain travel distance and time per trip for residents in whole city and in the west regions. The average distance per trip is an indicator of network performance, illustrating the trip demand. A longer average travel distance in each trip therefore also means more demand and congestion. The PT passengers in the west region have the smallest average distance compare to other modes.

Table 6: Average distance per trip for all alternatives.

\begin{tabular}{|l|l|l|l|l|l|l|}
\hline Region & $\begin{array}{l}\text { Trans } \\
\text { port } \\
\text { mode }\end{array}$ & $\begin{array}{l}\text { Base } \\
\text { case } \\
2010\end{array}$ & $\begin{array}{l}\text { Current } \\
\text { trend } \\
2030\end{array}$ & $\begin{array}{l}\text { Improvement } \\
\text { of MRT \& } \\
\text { LRT in 2030 }\end{array}$ & $\begin{array}{l}\text { Imp. of } \\
\text { PT in } \\
2030(\%)\end{array}$ & $\begin{array}{l}\text { Space- } \\
\text { transport } \\
\text { development }\end{array}$ \\
\hline \multirow{2}{*}{$\begin{array}{l}\text { West } \\
\text { region }\end{array}$} & PT & 13.2 & 25.34 & 11.59 & 11.65 & 11.72 \\
\cline { 2 - 7 } & MC & 12.22 & 26.71 & 35.78 & 37.41 & 39.56 \\
\cline { 2 - 7 } & Car & 13 & 19.23 & 13.37 & 17.46 & 13.62 \\
\hline \multirow{2}{*}{$\begin{array}{l}\text { Entire } \\
\text { of city }\end{array}$} & PT & 12.41 & 22.78 & 20.5 & 20.83 & 19.89 \\
\cline { 2 - 7 } & MC & 11.56 & 14.52 & 14.49 & 16.65 & 15.59 \\
\cline { 2 - 7 } & Car & 11.27 & 13.4 & 11.3 & 11.77 & 12.02 \\
\hline
\end{tabular}


Table 7: Average travel time per trip for all alternatives.

\begin{tabular}{|l|l|l|l|l|l|l|}
\hline Region & $\begin{array}{l}\text { Trans } \\
\text { port } \\
\text { mode }\end{array}$ & $\begin{array}{l}\text { Base } \\
\text { case } \\
2010\end{array}$ & $\begin{array}{l}\text { Current } \\
\text { trend } \\
2030\end{array}$ & $\begin{array}{l}\text { Improvement of } \\
\text { MRT \& LRT in } \\
2030(\%)\end{array}$ & $\begin{array}{l}\text { Imp. of } \\
\text { PT in } \\
2030(\%)\end{array}$ & $\begin{array}{l}\text { Space- } \\
\text { transport } \\
\text { development }\end{array}$ \\
\hline \multirow{2}{*}{$\begin{array}{l}\text { West } \\
\text { region }\end{array}$} & PT & 58.5 & 150.3 & 69.43 & 67.6 & 71 \\
\cline { 2 - 7 } & MC & 35.8 & 193.6 & 87.61 & 85 & 96.3 \\
\cline { 2 - 7 } & Car & 42.1 & 265.3 & 124.88 & 121.5 & 143.7 \\
\hline \multirow{2}{*}{$\begin{array}{l}\text { Entire } \\
\text { of city }\end{array}$} & PT & 55.9 & 114 & 61.52 & 61.38 & 63.9 \\
\cline { 2 - 7 } & MC & 46 & 149.3 & 82.17 & 82.26 & 95.4 \\
\cline { 2 - 7 } & Car & 59.4 & 209.3 & 119.07 & 119.8 & 141.5 \\
\hline
\end{tabular}

Average travel time is highest for the public transport passengers in base case 2010. By designing improvement of PT-systems, an average travel time for each trip reduces depending on the alternative. Travel time indicating the network performance lessens with improvement of PT system. This situation has an effect on increase of the willingness to use of PT. The alternative relating to the improvement of all PT-systems is expected to minimize average travel time for residents in the west region of city. The proposed huge increase of PT in those areas illustrates residents' prospective willingness to use PT in stated of relying on private vehicles. Reducing travel time for each trip in those areas also explains the performance of PT (public transport) network is more attractive than the other transport modes.

As mentioned in Table 5, modal split with improvement of PT-system also increases with indicated value approximately 1.5 times the use possibility of PTsystem. Travel time in this alternative is the shortest of all other alternatives. Briefly, this alternative performs well, reducing travel time by $40 \%$ and increasing passengers use public transport by 1.5 times.

\section{Conclusions and recommendations}

During the last thirty years, the settlement has been expanding into the suburbs. As a consequence, commuting trips using private vehicle such as car and motorcycle have increase to the central urban areas. The central urban areas have retained a strong attraction for the commuter from the suburb.

Under heterogeneous traffic conditions, the variation of the PCU value is estimated by using microscopic data by employing porous flow approach [11]. The PCU value decreases with the increase of speed. Using data from questionnaires, estimation of distribution parameters has been measured by employing a top-lognormal distribution function. Similar data are used to determine the VOT which is analyzed by mode choice approach.

The findings from evaluating the alternative of space-transport development have significant difference in modal split. Firstly, the transport mode choice is very dependent on the improvement alternatives for PT systems. If the quality of PT system were sufficiently high, the willingness to change to PT system would 
increase considerably because of the reduction of the average travel time per trip. Secondly, the balance between employment and population density linked to the PT system has an effect on reducing use of car and increasing the change of transport mode, particularly public transport and bicycle. This result means that settlement development and work place should be connected with high accessibility.

Future research will examine the space-transport development such as design of balance of job and housing distance intended to reduce commuting time, assessment of air quality impact, and consideration of residents' preference in evaluating the PT performances and living conditions.

\section{References}

[1] Duncan, J., The Search for Efficient Urban Growth Patterns: A Study of the Fiscal Impacts of Development in Florida, Tallahassee: Florida Department of Community Affairs. 1989.

[2] Banister, D., Energy, quality of life and the environment: the role of transport. Transport Reviews, 16 (1), pp. 23-35, 1996.

[3] FHWA, An Overview Land Use and Economic Development in Statewide Transportation, Center for Urban Transportation Studies, University of Wisconsin, Milwaukee, In Cooperation with Wisconsin Department of Transportation, 1999.

[4] Vega, A. \& Reynolds-Feighan, A Methodological Framework for the Study of Residential Location and Travel-to-Work Mode Choice Under Central and Suburban Employment Destination Patterns, Transport Research part A 43, pp. 401-419, 2009.

[5] Gennaio M.P., Hersperger A. M. \& Burgi, M., Containing urban sprawlEvaluating effectiveness of urban growth boundaries set by the Swiss Land Use Plan, Land Use Policy 26, pp. 224-232, 2009.

[6] Terzi, F. \& Bolen, F., The Potential Effects of Spatial Strategies on Urban Sprawl in Istanbul. Urban Studies, 49 (6), 1229-1250, 2012.

[7] Aguiléra, A., Wenglenski, S. \& Proulhac, L., Employment suburbanisation, reverse commuting and travel behaviour by residents of the central city in the Paris metropolitan area. Transportation Research Part A: Policy and Practice, 43, 685-691, 2009.

[8] Statistic Bureau of Surabaya City, Surabaya City in Figures (in Indonesian), Surabaya, 2010.

[9] Grashoff, P. \& Zondag, B., Documentation of methodology for spatial projections: Java Spatial Model. Delft: DEMIS, 2010.

[10] Bovy, P., Bliemer, M., \& Nes, R. v., Transportation Modeling, Delft: Delft University of Technology, 2006.

[11] Ambarwati, L., Pel, A.J., Verhaeghe, R. \& Arem. B.V., Empirical Analysis of Heterogeneous Traffic Flow, Proceedings of the Eastern Asia Society for Transportation Studies, Vol. 9, 2013. 
[12] Arasan, V.T. \& Arkatkar, S.S., "Microsimulation study of vehicular interactions on heterogeneous traffic flow on intercity roads", European Transport/Trasporti Europei, 48, pp. 60-86, 2011.

[13] Wanga, D., Feng, T., \& Liang, C., Research on bicycle conversion factors. Transportation Research Part A: Policy and Practice, 42, 1129-1139, 2008.

[14] Department of Transport of Surabaya City, Surabaya MRT: Surabaya Mass Rapid Transportation (SMART), Technical Report Surabaya, Indonesia, 2013. 